\title{
Thymine Starvation and Genetic Damage in Escherichia coli
}

\author{
By M. G. R. HART \\ Department of Botany, The Queen's University, Belfast, Northern Ireland
}

(Received 2 May 1966)

\section{SUMMARY}

Two thy- Hfr strains of Escherichia coli $\mathrm{k} 12$ were mated with stationary phase $\mathrm{w}^{677} \mathrm{~F}^{-}$at intervals during thymine starvation. With both strains, Hfr bacteria retained their capability of chromosome transfer for a period after loss of colony-forming ability. Eventual loss of transfer capability in strain $\mathrm{HfrC}$ thy- was associated with inactivation of some early stage of the transfer process. Thymine starved HfrC thy- transferred the genetic markers pro, thr, leu and thi with a normal gradient but HfrB1 thy-showed marker inactivation. The extent of marker inactivation in this strain was consistent with the presence of 10-20 breaks/chromosome. It is suggested that the strains may have behaved differently in these experiments as a result of differences in their ability to modify primary genetic lesions resulting from thymine starvation.

\section{INTRODUCTION}

Evidence has accumulated which suggests that 'thymineless death' (Cohen \& Barner, 1954) may be associated with nuclear damage. Maaløe (1961) showed that the susceptibility of a bacterium to thymineless death was dependent on its ability to synthesize DNA at the time thymine was withdrawn. Fuerst \& Stent (1956) showed that the lethal effects of thymine starvation and the decay of ${ }^{32} \mathbf{P}$ in the bacterial nucleus were additive. Others (Gallant \& Suskind, 1961; Rassmussen \& Painter, 1963) showed a similar connection between the effects of thymine starvation and ultraviolet (u.v.) irradiation. Stacey, Symonds \& Atkinson (1966) reported a number of other similarities between u.v. death and thymineless death. Several groups have reported a mutagenic effect of thymine starvation (Coughlin \& Adelberg, 1956; Weinberg \& Latham, 1956; Kanazir 1958) though this has not been confirmed in the present author's laboratory using thymine- strains of Escherichia coli $\mathrm{x} 12$, all of which died rapidly under conditions of thymine deprivation.

Attempts to obtain specific evidence about possible nuclear damage have been rather unsuccessful. Luzatti \& Revel (1962) detected no physical differences between normal and 'thymineless' DNA. Freifelder \& Maaløe (1964), who used a technique which had been successful in detecting single-strand breaks in T bacteriophage DNA (Davison, Freifelder \& Holloway, 1964) obtained no evidence for such breaks in the DNA extracted from thymine-starved bacteria. However, DNA extracted from thymine-starved Bacillus subtilis showed a decreased efficiency of transformation (Sicard \& Anagnostopoulos, 1964). Meningmann \& Sybalski (1962) also obtained this effect with DNA extracted from $B$. subtilis treated with 5 -fluorodeoxyuridine as an inhibitor of thymidylate synthetase; the presence of single-strand breaks was inferred from sedimentation data and viscosity measurements. However, in such 
experiments it is difficult to rule out the possible effects on the bacterial DNA of normal or defective prophages which are induced as a consequence of thymine deprivation (Korn \& Weissbach, 1962; Melechen \& Skaar, 1962; Sicard \& Devoret, 1962).

Jacob \& Wollman (1958), in their experiments on the conjugation process, were able to show that ${ }^{32} \mathrm{P}$ decay within the Hfr nucleus and $\mathrm{u} . v$. irradiation of the Hfr bacterium before mating had distinctive effects on the genetic continuity of the chromosome. Intranuclear ${ }^{32} \mathrm{P}$ decay caused inactivation of the various genetic markers, increasing the steepness of the normal gradient of transfer. U.v. irradiation of the male cell did not affect the transfer process, but decreased the extent to which portions of chromosome carrying more than one marker were integrated into recombinant genotypes.

Because of the related effects of thymine starvation, intranuclear ${ }^{32} \mathrm{P}$ decay and u.v. irradiation, it might be expected that they would influence transfer and recombination in a similar way. The experiments to be described were undertaken to investigate this possibility.

\section{METHODS}

Organisms. The following strains of Escherichia coli were used; K12 HfrC thymet- $(\lambda)+\lambda$-sens str-s, transferring chromosomal markers in the order-origin, pro (10 min.) leu, thr, thi; $\mathrm{k} 12 \mathrm{HfrB1}$ (Broda) thy- met- $(\lambda)^{-} \lambda$-res str-s transferring chromosomal markers in the order-origin, pro (5 min.), leu, thr, thi; $15 \mathrm{~T}^{-}$thy- (Cohen \& Barner, 1954); к 12 w 677 pro $^{-}$thr- leu- thi- str-r $\mathrm{F}^{-}$. The thy- strains of HfrC and HfrB1 were obtained using aminopterin (Okada, Yanagisawa \& Ryan, 1961) and both had a high requirement for thymine (50 $\mu \mathrm{g} . / \mathrm{ml}$.$) . Abbreviations: leu-$ leucineless, met ${ }^{-}$--methionineless, pro $^{-}$- prolineless, sens - sensitive, str-s - streptomycin sensitive, $s t r-r$ - streptomycin resistant, $t h i^{-}$- thiamineless, $t h r^{-}$- threonineless, thy--thymineless.

Culture media. Bacteria were grown in Oxoid Nutrient Broth No. 2 or in minimal M9 medium containing (g./l.) $\mathrm{Na}_{2} \mathrm{HPO}_{4}, 6 ; \mathrm{KH}_{2} \mathrm{PO}_{4}, 3 ; \mathrm{NaCl}, 0.5 ; \mathrm{NH}_{4} \mathrm{Cl}, 1 ; \mathrm{MgSO}_{4}$, 0.2 ; glucose, 4 ; dissolved in 11 . distilled water. Amino acid supplements were added to $\mathrm{M} 9$ medium at a final concentration of $20 \mu \mathrm{g} . / \mathrm{ml}$. and thiamin at $0.2 \mu \mathrm{g} . / \mathrm{ml}$. Thymine was used in nutrient and minimal media at $80 \mu \mathrm{g} . / \mathrm{ml}$.

'Thymineless broth' was nutrient broth in which Escherichia coli $15 \mathrm{~T}^{-}$had been grown until extensive filamentation was observed. Two periods of growth, each followed by centrifugation and re-autoclaving were necessary to obtain deficiency symptoms indicative of a low thymine content of the broth.

Oxoid Blood Agar Base No. 2 with added thymine was used for colony counts of viable bacteria.

Recombinants were assayed by plating on G and T agar (Okada et al. 1961) with appropriate nutrient supplements, nutrient broth $0.5 \%, \mathrm{v} / \mathrm{v}$ (Gross, 1963) and streptomycin $250 \mu \mathrm{g} . / \mathrm{ml}$.

Growth of cultures. Cultures of all strains were prepared by inoculation of part of a single colony from a recently prepared streak plate into a complete liquid medium and gently agitated during overnight incubation. Log phase cultures were prepared from overnight cultures by diluting $1 / 10$ into similar medium prewarmed to $37^{\circ}$ and incubating with aeration for $90 \mathrm{~min}$. 
Thymine starvation. Transfer of bacteria to thymine-deficient medium was made by using membrane filtration. Bacteria were washed three times in thyminedeficient medium before re-suspension. All operations were done at $37^{\circ}$; all media and equipment were pre-warmed to this temperature before use.

Mating procedure. A sample $(\mathbf{0 . 2} \mathrm{ml}$.) of $\mathrm{Hfr}$ suspension was added to a mixture of $1 \mathrm{ml}$. overnight culture of Escherichia coli w677 in unsupplemented broth and $1 \mathrm{ml}$. fresh broth supplemented with $160 \mu \mathrm{g} . / \mathrm{ml}$. thymine. The mixture was rotated gently on an inclined turntable for $1 \mathrm{hr}$. Samples were then removed for plating.

Pairing experiments. Experiments on pair formation were made by the technique of Jacob \& Wollman (1961).

Pulse mating was done by the method of de Haan \& Gross (1962).

\section{RESULTS}

\section{Effects of thymine starvation on recombinant formation by $\mathrm{HfrC}$ thy-}

Figure 1 shows the results of mating $\mathrm{HfrC}$ thy- bacteria at intervals during thymine starvation, together with the viability loss which occurred. No inactivation of the markers thr leu was obtained relative to the marker pro. Isolation and testing of a number of $\mathrm{pro}^{+}$colonies gave no indication of a decreased frequency of transfer of the thi character by thymine-starved bacteria. Other experiments showed that the rate of decline of $\mathrm{pro}^{+}$thi $i^{+}$recombinants was the same as that of $\mathrm{pro}^{+}$. In this strain, the kinetics of transfer and recombination were apparently unaffected by thymine starvation.

Viability of the HfrC population declined more readily than the number of recombinants which it produced and after about $3 \mathrm{hr}$, the number of recombinants $/ \mathrm{ml}$. of the mating mixture was almost the same as the number of viable $\mathrm{HfrC}$ bacteria. This could have resulted from a greatly increased efficiency of recombinant formation by the surviving bacteria, from a selection against a non-fertile fraction of the $\mathrm{Hfr}$ population by the lethal action of thymine starvation, or from a participation in the recombination process by 'dead' bacteria unable to form colonies. Recombination by 'dead' bacteria is most likely as in later experiments (Fig. $5 b$ ) with HfrB1 thy- $(\lambda)^{-}$the number of recombinants formed by thymine-starved populations greatly exceeded the number of viable male bacteria present. The method therefore allows an examination of the kinetics of transfer by 'dead' bacteria and should be capable of detecting genetic damage accompanying thymineless death. Plating on minimal medium or incubation at $42^{\circ}$ or $25^{\circ}$ did not give significantly different estimates of viability. With strain $\mathrm{HfrC}$ thy-, the discrepancy between the rates of viability loss and fertility loss was not so great when minimal medium was used and experiments were therefore always made with broth media.

The discrepancy in rates did not persist. When thymine-starved bacteria were incubated for $\mathbf{3 0} \mathrm{min}$. in thymine-supplemented broth before mating the results shown in Fig. 2 were obtained. No marker inactivation occurred but the rates of loss of viability and fertility were similar. The $30 \mathrm{~min}$. treatment in complete medium had resulted in loss of fertility by the dead bacteria. This was confirmed in an experiment in which bacteria starved of thymine for $180 \mathrm{~min}$. were incubated in complete medium for various periods before mating. The results are shown in Fig. 3. A decrease in fertility of the thymine-starved bacteria occurred for a 
15-20 min. period, after which no decline was observed. A small increase in viable count (less than one doubling) occurred during the $\mathbf{3 0} \mathrm{min}$. period of the experiment. The rate of loss of fertility in this experiment was higher than that which normally occurred during thymine starvation (see Figs. 1, 2). Possibly DNA synthesis accelerated the decline.

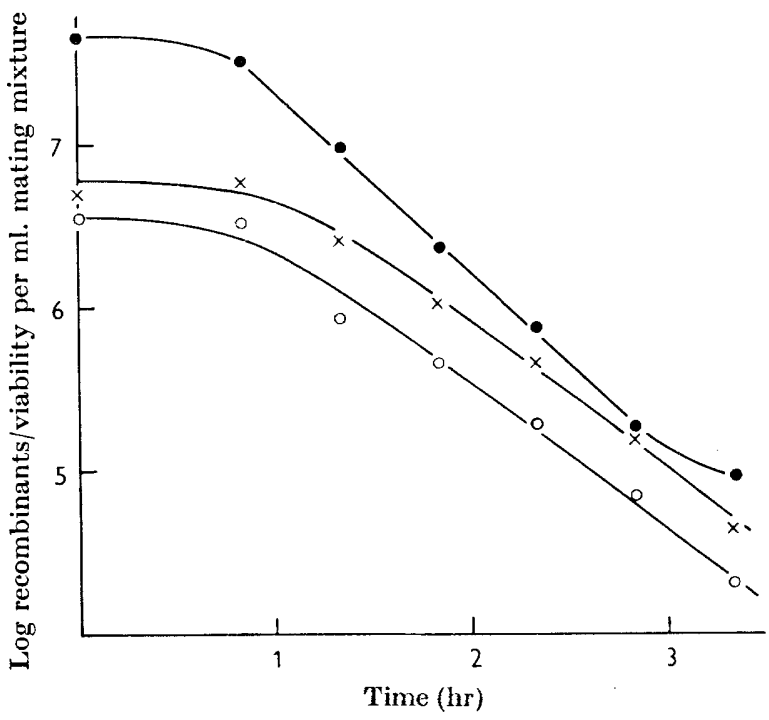

Fig. 1

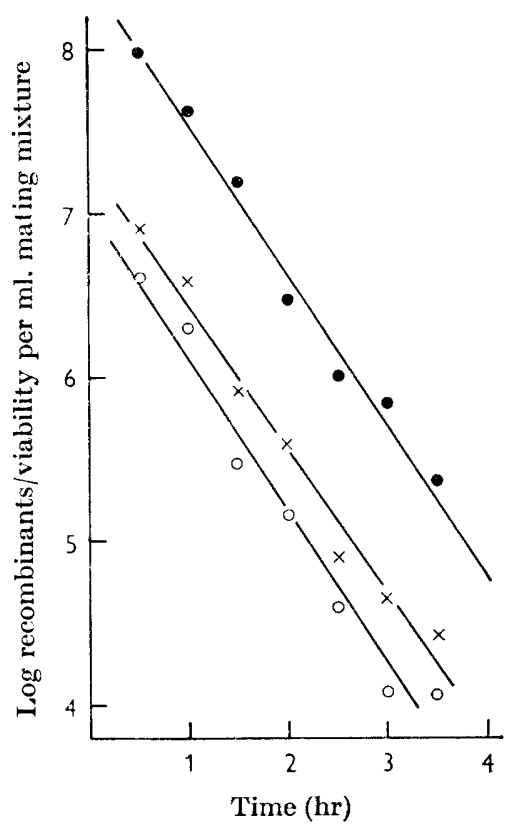

Fig. 2

Fig. 1. Viability loss and recombinant formation by thymine-starved HfrC thy - A $10 \mathrm{ml}$. $\log$ phase culture of $\mathrm{HfrC} t h y^{-}$in thymine-supplemented broth was washed and resuspended in the same volume of thymineless broth. Samples were taken at intervals during thymine starvation for $(a)$ colony counts, $(b) 60$ min. mating with w677 and subsequent plating for pro $^{+}$and $t h r^{+} l e u^{+}$recombinants. Log viable count $-\longrightarrow, \log$. pro $^{+} \times-\times$and $\log t h r^{+} l e u^{+} \mathrm{O}-\mathrm{O}$ are given per ml. of the mating mixture which contained: $0.2 \mathrm{ml}$. HfrC in thymineless broth, $1 \mathrm{ml}$. overnight culture of $w 677$ in unsupplemented broth and $1 \mathrm{ml}$. fresh broth supplemented with $160 \mu \mathrm{g} . / \mathrm{ml}$. thymine.

Fig. 2. Effect of pre-incubation in complete medium before mating on recombinant formation by thymine-starved HfrC thy- bacteria. Experimental procedure and symbols as in Fig. 1. except that samples of the $\mathrm{HfrC}$ suspension were held at $37^{\circ}$ with added thymine $\left(80 \mu \mathrm{g} . / \mathrm{ml}\right.$.) for $30 \mathrm{~min}$. before the addition of the $\mathrm{F}^{-}$bacteria.

\section{The stage of the conjugation process affected by thymine starvation}

The results suggest that thymineless death occurred in at least two recognizable stages; a first stage in which the bacterium lost ability to form colonies (it has so far not been possible to devise conditions which will reverse this step in this strain; M. H. L. Green, personal communication), and a second stage in which the bacterium loses ability to form recombinants. Possible ways in which the bacterium might be damaged in the second stage are as follows: $(a)$ those which interrupt the transfer process and result in apparent marker inactivation, e.g. chromosome breakage, pair instability resulting in premature separation, metabolic failure, lysis; $(b)$ those 
which prevent initiation of transfer but do not affect the process of transfer itself, e.g. inability to form effective pairs as a result of nuclear damage of a kind which would not cause marker inactivation. The fact that marker inactivation did not occur makes $(a)$ damage less likely and suggests that the second stage during which fertility was lost might result from specific damage to the pairing or transfer mechanism.

Figure $4 a$ shows the result of a pulse-mating experiment with HfrC thy- bacteria starved of thymine for $180 \mathrm{~min}$. Except for a small increase in the time of entry of the proline marker, which might have been due to a thymine requirement in transfer

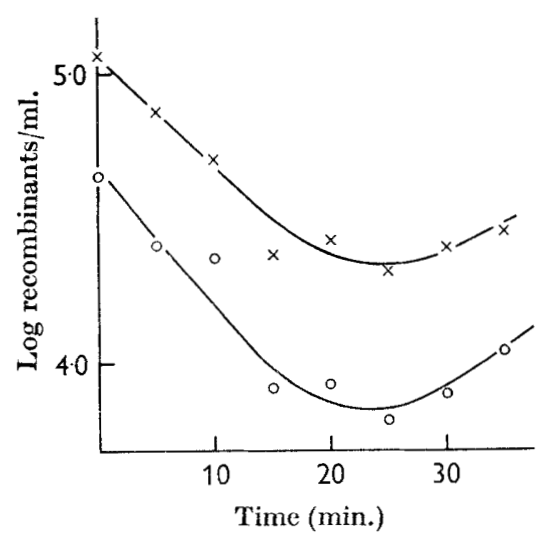

Fig. 3

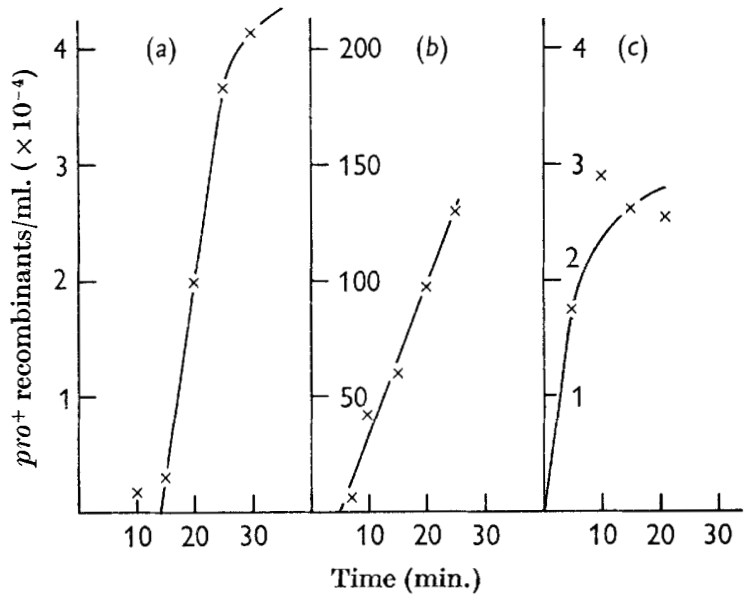

Fig. 4

Fig. 3. Eflects of periods of incubation in broth + thymine on recombinant formation by thymine starved HfrC thy- bacteria. Symbols as in Fig. 1. HfrC thy- bacteria starved of thymine for $3 \mathrm{hr}$ in $t h y^{-}$broth, then $80 \mu \mathrm{g} . / \mathrm{ml}$. thymine added and cultures held at $37^{\circ}$ for various intervals before mating with $w 677$ as in Fig. 1 procedure.

Fig. 4. (a) Pulse mating experiment showing increase of pro $^{+}$recombinants after mating HfrC thy starved of thymine $3 \mathrm{hr}$. (b) Pair formation by normal bacteria of HfrC thy- . (c) Pair formation by $\mathrm{HfrC}$ thy- after $3 \mathrm{hr}$ thymine starvation.

initiation (Pritchard, 1965) the kinetics of transfer are normal for this type of experiment. The 15 min. spread of transfer times found by de Haan \& Gross (1962) occurred and there was no suggestion of a decrease in the rate at which new transfers were initiated during this 15 -min. period. Damage of type $(a)$ excluding actual chromosome breakage might be expected to cause a decrease in the rate of initiation of new transfers. Such experiments lend support to the idea that genetic transfer by 'thymineless dead' bacteria is not inactivated once effective pairs have been formed.

The results of pairing experiments also suggest that the decline in fertility which occurred in HfrC thy- after thymineless death was the result of loss of ability to form effective pairs. Figures $4 b$ and $4 c$ show the results of pairing experiments with this strain after 0 and $180 \mathrm{~min}$. of thymine starvation. The ability of the thyminestarved population to form effective pairs was greatly decreased with time, whilst the unstarved population retained its initial pair forming ability. 


\section{Effects of thymine starvation on recombinant formation by strain HfrB1 thy-}

A second Hfr strain, B1 thy-, which was $(\lambda)^{-} \lambda^{-}$res and therefore not susceptible to induction of phage $\lambda$ during thymine starvation was chosen for comparison. This strain did not lyse when thymine was returned after a period in thymineless broth, but its behaviour in minimal medium indicated that the presence of defective prophages was not entirely eliminated. HfrB1 transfers almost the same piece of chromosome as $\mathrm{HfrC}$, and with the same orientation.
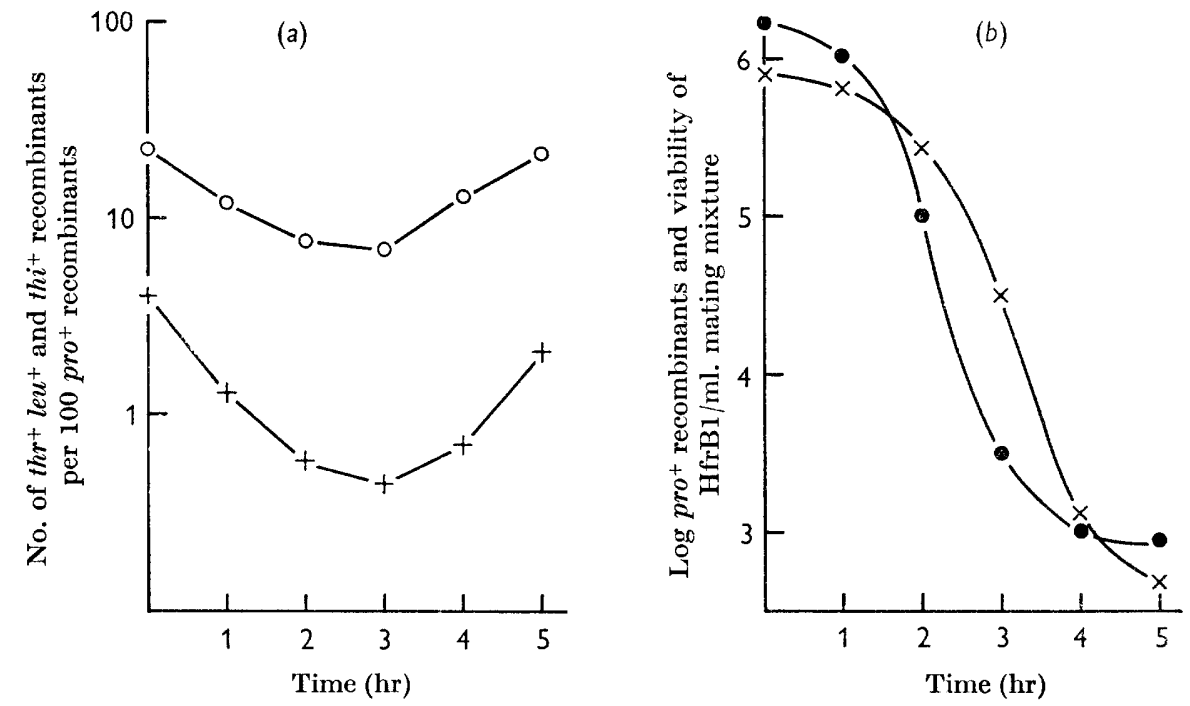

Fig. 5. (a) Effect of thymine starvation of $\mathrm{HfrB} t h y^{-}$on the proportion of distal markers inherited in crosses with $\mathrm{w} 677$. (b) Viability loss and recombinant formation by thymine starved HfrB1 thy- ${ }^{-}$Method for both Fig. 5 $(a)$ and $(b)$ was as described for Fig. 1 except that the Hfr strain was grown overnight in minimal medium, brought to log phase in $10 \mathrm{ml}$. of the same medium and the whole volume re-suspended in $50 \mathrm{ml}$. minimal medium minus thymine after filtration and washing.

Marker inactivation was obtained with this strain. Figure $5 a$ shows the decline in the percentage of the distal markers inherited, relative to the number of pro $^{+}$ recombinants. No decrease in the proportion of $\mathrm{pro}^{+} t h i^{+}$recombinants relative to the number of $t h i^{+}$occurred. The degree of marker inactivation increased to a maximum at $180 \mathrm{~min}$, after which it declined. At $300 \mathrm{~min}$. the figures are close to those obtained using unstarved bacteria. This indicates that transfer by the immune fraction of the population was normal and that marker inactivation was restricted to that fraction of bacteria which were incapable of colony formation. The time of maximum marker inactivation coincided with the time at which most dead bacteria were still capable of transfer (Fig. $5 b$ ).

If the 'immune' bacteria are neglected, and it is assumed that the amount of marker inactivation observed is entirely due to random chromosome breaks, it can be calculated that between 10 and 20 breaks/transferred chromosome would be present. This estimate would be well below the limit of detection quoted by Freifelder \& Maaløe (1964). 
One cannot be entirely certain that marker inactivation is not the result of some factor other than chromosome breakage. Decreased stability of mating pairs, stoppage of transfer or decreased rate of transfer would all give similar results. However, it is difficult to reconcile the absence of marker inactivation in strain HfrC thy with any of these explanations. In addition, pulse-mating experiments with strain HfrB1 thy gave identical results whether with starved or unstarved bacteria. No decline in the rate of increase of recombinants during the $15 \mathrm{~min}$. spread was detected and thymine starvation had no effect on the time of entry of successive markers indicating that the rate of transfer was unchanged in thyminestarved populations.

\section{DISCUSSION}

With both Hfr strains of Escherichia coli there was a clear separation between the stage at which a bacterium was no longer able to form colonies and its loss of fertility. The absence of marker inactivation in HfrC suggests that fertility was eliminated by damage specifically affecting transfer initiation or functions associated with it. Nuclear damage may be involved, though the results give no indication as to whether such damage would be the primary cause of thymineless death.

No evidence was obtained in either strain for a stimulation of recombination such as has been demonstrated by Jacob \& Wollmann (1958) with u.v. irradiation of donor strains or ${ }^{32} \mathbf{P}$ decay in zygotes. This is surprising since Gallant \& Spottswood (1965) showed strong recombinogenic effect of thymine starvation in Escherichia coli merodiploids. The results of the present experiments suggest that if genetic damage is transferred in the donor fragment it has no effect on the activity of the recombinase systems of the recipient. The final outcome may depend on some characteristic of the recipient bacterium used.

If the marker inactivation observed in strain $\mathrm{HfrBl}$ thy- is entirely a consequence of chromosome breaks, the results are not compatible with the suggestion of Maaløe (1961) that thymine starvation might cause damage at the replicating point. This hypothesis would predict a single break/chromosome in bacteria having a single replicating point, and the amount of inactivation observed could only be accounted for on a single-hit hypothesis if the damage was very extensive. A number of individual lesions, possibly occurring during transcription as suggested by Galland \& Suskind (1962), would seem to be more likely.

A possible explanation for the difference observed between the two strains may lie in a differing ability to modify primary genetic lesions. Single strand breaks blocking transfer might occur as a result of the activity of an enzyme such as that which has been shown to excise pyrimidine dimers in u.v. irradiated Escherichia coli (Setlow \& Carrier, 1964). Thymine deprivation might prevent completion of the repair by preventing DNA synthesis on the remaining single strand template; a single strand gap which prevented chromosome transfer would thus be produced. Preliminary experiments with HfrBl thy- have shown that marker inactivation can be produced by u.v. irradiation followed by a short period of thymine starvation. Experiments now in progress suggest that the strains used in the present experiments and their parent thy ${ }^{+}$strains do differ in their ability to repair u.v. induced lesions.

The author gratefully acknowledges the assistance of Miss Marie Meehan, B.Sc. 


\section{REFERENCES}

Cohen, S. S. \& BARNer, H. D. (1954). Studies on unbalanced growth in Escherichia coli. Proc. natn. Acad. Sci. U.S.A. 40, 885.

Coughlin, C. A. \& Adelderg, E. A. (1956). Bacterial mutation induced by thymine starvation. Nature, Lond. 178, 531.

Davison, P. F., Freifelder, D. \& Holloway, B. W. (1964). Interruptions in the polynucleotide strands of bacteriophage DNA. J. mol. Biol. 8, 1.

Freifelder, J. D. \& MaAløe, O. (1964). Energy requirement for thymineless death in cells of Escherichia coli. J. Bact. 88, 987.

Fuenst, C. R. \& STEnT, G. S. (1956). Inactivation of bacteria by decay of incorporated radioactive phosphorus. $J$. gen. Physiol. 40, 73.

Gallant, J. \& SpotTswood, T. (1965). The recombinogenic effect of thymidylate starvation in Escherichia coli merodiploids. Genetics 52, 107.

Gallant, J. \& Suskind, S. R. (1961). Relationship between thymineless death and ultraviolet inactivation in Escherichia coli. J. Bact. 82, 187.

Gallant, J. \& Suskind, S. R. (1962). R.N.A. synthesis and thymineless death. Biochim. biophys. Acta 55, 627 .

Gross, J. D. (1963). The effect of unbalanced growth on recombinant formation in Escherichia coli. Genet. Res. 4, 457.

de HAan, P. G. \& Gross, J. D. (1962). Transfer delay and chromosome withdrawal during conjugation in Escherichia coli. Genet. Res. 3, 251.

JACOB, F. \& Wollman, E. L. (1958). Genetical and physical determinations of chromosomal segments in Escherichia coli. Symp. Soc. exp. Biol. 12, 75.

$\mathrm{J}_{\mathrm{Acob}}$, F. \& Wollman, E. L. (1961). Sexuality and The Genetics of Bacteria. p, 137. New York: Academic Press.

Kanazir, D. (1958). Apparent mutagenicity of thymine deficiency. Biochim. biophys. Acta 30, 20.

Konn, D. \& Weissbach, A. (1962). Thymineless induction in Escherichia coli $\mathbf{k} 12(\lambda)$. Biochim. biophys. Acta 61, 775.

Luzatti, D. \& Revel, C. (1962). Effet léthal de la carence en thymine: état de l'acide deoxyribonucléique au cours de cette carence. Biochim. biophys. Acta $61,305$.

MAaLøe, O. (1961). The control of normal DNA replication in bacteria. Cold Spring Harb. Symp. quant. Biol. 26, 45.

Melechen, N. E. \& SkaAR, P. D. (1962). The provocation of an early step of induction by thymine deprivation. Virology 16, 21.

Mennigmane, H. \& Sybalskr, W. (1962). Molecular mechanism of thymineless death. Biochem. biophys. Res. Comm. 9, 398.

Okada, T., Yanagisawa \& RYan, F. J. (1961). A method for securing thymineless mutants of Escherichia coli. Z.-Vererbungslehre 92, 403.

Pritchard, R. H. (1965). The relationship between conjugation, recombination and DNA synthesis in Escherichia coli. 10th Int. Congress Genetics. Genetics Today 2, 56.

Rasmussen, R. E. \& Painter, R. B. (1963). On the early onset of thymineless death occurring after exposure to ultra-violet light. Biochim. biophys. Acta 76, 157.

Setlow, R. B. \& Carrier, W. L. (1964). The disappearance of thymine dimers from DNA: an error correcting mechanism. Proc. natn. Acad. Sci. U.S.A. 51, 226.

Srcard, N. \& Anagnostopoulos, C. (1964). Activité transformante de l'acide desoxyribonucléique de Bacillus subtilis lors de la carence en thymine. C. r. Acad. Sci. Paris $259,4173$.

Sicard, N. \& Devoret, R. (1962). Effets de la carence en thymine sur les souches $d$ 'Escherichia Coli lysogènes K 12 $\mathrm{T}^{-}$et colicinogène $15 \mathrm{~T}^{-}$. C. r. Acad. Sci. Paris 255, 1417.

Stacey, K. A., Symonds, N. D. \& Atkinson, C. (1966). (In Press.)

Weinberg, R. \& Latham, A. B. (1956). Apparent mutagenic effect of thymine deficiency for a thymine requiring strain of $E$. coli. J. Bact. 72, 570 . 